\title{
O PROTAGONISMO JUVENIL COMO FORMA DE REAPROXIMAR O ADOLESCENTE DA LEITURA
}

\section{YOUTH PROTAGONISM AS A WAY TO RECONNECT ADOLESCENTS TO READING}

Thais Batista Siqueira ${ }^{1}$

\begin{abstract}
Resumo: O objetivo deste artigo é investigar se a promoção do protagonismo juvenil reaproxima os adolescentes dos anos finais do ensino Fundamental $2\left(8^{\circ}\right.$ e $9^{\circ}$ anos) das práticas de leitura. Privilegia-se os estudantes $8^{\circ}$ s e $9^{\circ}$ s anos pelo fato de ser esta a faixa etária na qual as pesquisas Retratos da Leitura no Brasil mostram queda no gosto pela leitura. Adotamos como referencial teórico os trabalhos de Calligaris (2013), Becker (2003), Petit (2013) e Butlen (2015) e os dados produzidos pela série de pesquisas acima mencionada. Analisamos ainda entrevista e produção textual de um adolescente de $9^{\circ}$ ano, obtidas em trabalho de campo realizado em sala de leitura de uma escola municipal da cidade de São Paulo, utilizando a abordagem qualitativa (estudo de caso).
\end{abstract}

Palavras-chave: Práticas de leitura; protagonismo juvenil; adolescência.

Abstract: The article's purpose is to investigate if the promotion of youth protagonism reconnects Fundamental 2 adolescents to reading. We favor last years students (8th and 9th grades) because this is the age group that the research Retratos da Leitura no Brasil shows decrease in reading. As theoretical references we adopt the works by Calligaris (2013), Becker (2003), Petit (2013) and Butlen (2015) and the data produced by the research already mentioned. We have also analyzed one 9th grade adolescent's interview and composition, obtained through field research that took place in a public school reading room from São PauloCapital, using qualitative analysis (case atudy).

Keywords: Reading practices; youth protagonism; adolescence.

\section{Não vou me adaptar}

Parafraseando o artista Paul Klee, os adolescentes me percebem. E, obviamente, eu os percebo também. Talvez muito mais do que eles me perceberam ao longo destes 10 anos atuando como professora da rede municipal de ensino paulistana. Aliás, não há como não percebê-los. Eles se fazem visíveis o tempo todo. Ruidosos, ainda adaptando-se às mudanças físicas e emocionais, ambivalentes, geralmente dispersos e imaturos, incontroláveis. Mas também afetuosos, dispostos, questionadores, criativos, potentes. Toda essa adjetivação, é bom salientar, advém da perspectiva adulta.

Ser professor de adolescentes não é tarefa desejada por muitos. As exigências e os desafios são enormes e a recompensa nem sempre é percebida por todos os profissionais. Em alguns momentos, ser professor de adolescentes é entrar em contato com sua própria história enquanto estudante; espero que não para repeti-la, mas para superá-la ou problematizá-la. É entender em qual momento uma intervenção pode ser bem-vinda ou quando é melhor calar-se. Que algumas vezes não será possível executar as atividades planejadas porque aparece uma outra necessidade pulsante e urgente.

\footnotetext{
${ }^{1} \mathrm{FE} /$ Unicamp.
} 
Tema de canções, filmes e livros, a adolescência encanta e preocupa os adultos na mesma medida. Para aqueles que a estão vivenciando, no entanto, o estranhamento pode ser maior do que as alegrias. Não vou me adaptar ${ }^{2}$, canção da banda de rock Titãs, é um exemplo desse sentimento de estranhamento experimentado pelo adolescente. $\mathrm{Na}$ canção, o personagem vivencia o luto pelas mudanças físicas e o fato de não ser mais visto como criança pelos familiares. Ele perdeu o lugar de afeto e proteção geralmente dedicados às crianças em nossa sociedade, não sendo mais o centro da atenção dos adultos, mas sim foco de conflitos ${ }^{3}$. Sofre para se adaptar ao seu novo momento e não percebe de imediato as mudanças externas e internas pelas quais passa. Parece pego de surpresa. Ele se sente inadequado por não ser mais criança, mas ainda não é tratado como adulto por não ser reconhecido enquanto tal.

Em A adolescência (2013), o psicanalista Contardo Calligaris conta uma história de ficção para construir o cenário da adolescência como moratória, um adiamento, um momento de suspensão entre a infância e a vida adulta ${ }^{4}$. Segundo essa história, a criança passa os 12 primeiros anos de sua vida reunindo uma série de aprendizados sociais e culturais e no momento que ela os colocaria em prática, recebe a notícia de que ainda não é o momento. Por que não é o momento? Por que se tornou necessário adiar a prática dos aprendizados?

Calligaris localiza o estabelecimento dessa idade da vida no início do século XX. Até então, certamente era possível se preocupar com o devir dos jovens, tanto físico quanto moral e econômico, mas "a adolescência" não era um fato social reconhecido: "Era uma faixa etária, mas não por isso um grupo social. Ainda menos um estado de espírito e um ideal da cultura" (2013, p. 60). O psicanalista e outros estudiosos do tema ${ }^{5}$ compartilham o entendimento da adolescência enquanto uma criação histórica da humanidade.

Neste sentido é imprescindível dizer que não existe uma ideia única de adolescência ou forma de vivenciá-la e tal premissa norteia este artigo. Ao apresentar uma experiência de trabalho com adolescentes localizados num determinado tempo, espaço e cultura, de maneira alguma pretendo que este grupo represente o todo das possibilidades de experiências adolescentes, pois, como afirma Becker, a ideia de que a adolescência seja um fenômeno universal é muito duvidosa (2003, p. 11).

\section{Por que falar sobre adolescência e leitura?}

Ingressei como professora na rede municipal de ensino de São Paulo em junho de 2010. No final deste mesmo ano, candidatei-me e fui eleita como Professora Orientadora de Sala de Leitura (POSL), função que exerci até o final de $2013^{6}$.

\footnotetext{
${ }^{2}$ Composta por Arnaldo Antunes e gravada pela primeira vez no álbum Televisão, de 1985. Esta canção também aparece em outros álbuns do grupo.

${ }^{3}$ Segundo Calligaris, o comportamento adolescente é considerado no mínimo anormal, por parecer (e de fato ser) transgressivo, quando comparado ao padrão adulto (o padrão confesso dos adultos). "Os adolescentes são facilmente considerados uma ameaça à ordem estabelecida e à paz familiar" (2013, p. 34).

${ }^{4}$ A ideia da adolescência enquanto moratória foi emprestada ao também psicanalista Erik Erikson (1902-1994), um dos responsáveis pela Teoria do Desenvolvimento Psicossocial na Psicologia e um dos teóricos da Psicologia do desenvolvimento. Esta teoria prediz que o crescimento psicológico ocorre através de estágios e fases, não ocorre ao acaso e depende da interação da pessoa com o meio que a rodeia. Cada estágio é atravessado por uma crise psicossocial entre uma vertente positiva e uma vertente negativa. As duas vertentes são necessárias, mas é essencial que se sobreponha a positiva. A forma como cada crise é ultrapassada ao longo de todos os estágios influenciará a capacidade para se resolverem conflitos inerentes à vida.

${ }^{5}$ Checchia (2014), César (1998), Lesourd (2004), Becker (2003) e Ozella (2003).

${ }^{6}$ O Programa Sala e Espaço de Leitura existe na rede paulistana desde 1972. Neste espaço são desenvolvidas atividades de leitura articuladas com a proposta pedagógica das salas de aulas regulares e com o projeto político pedagógico da escola. Ao longo desses mais de 45 anos de existência, o projeto passou por diversas transformações
} 
Desde o início do trabalho nesta função, percebi uma dificuldade em instigar nos educandos - adolescentes e jovens - o desejo de ler. Sempre encontravam uma desculpa para não emprestar os materiais de leitura e eu não acreditava que obrigá-los poderia favorecer esse relacionamento tão particular. Os alunos mais novos, no entanto, eram vorazes nos empréstimos, selecionando, inclusive livros não indicados para sua faixa etária.

Essa resistência dos educandos mais velhos me intrigava: por que a leitura não os interessava como antes? Será que o acervo estava defasado, o espaço não era atraente, as atividades propostas pouco estimulavam o empréstimo ou o trabalho com a leitura na escola era muito protocolar? Foi então que em meados de 2011, já me sentindo fracassada em minhas atribuições como formadora de leitores, me deparei com os livros da antropóloga francesa Michèle Petit ${ }^{7}$, enviados pelo MEC como parte do Programa Nacional Biblioteca na Escola para professores. A luz no fim do túnel finalmente se acendeu e voltei a enxergar possibilidades! Entendi que estudar seria a saída para os problemas detectados, mesmo que para isso fosse necessário comprar algumas brigas dentro da escola.

Por determinação da Portaria $\mathrm{n}^{\circ} 3.079$, de 23 de julho de 2008, em vigor durante o ano de 2011, precisei atender todas as etapas de ensino existentes na escola - Fundamental 1, Fundamental 2 e Médio. A diversidade e a peculiaridade de cada etapa de ensino me levaram a solicitar que alguns alunos do Fundamental 2 atuassem como monitores da Sala de Leitura, prática esta recorrente entre colegas de outras escolas da região.

Com idades entre 12 e 14 anos, estes alunos tinham a função de ajudar com as diversas atividades do espaço, sendo as principais a indicação de livros para empréstimo e a leitura de histórias para os alunos dos $1^{\circ} \mathrm{s}$ e $2^{\circ} \mathrm{s}$ anos do Fundamental 1, ainda em fase de contato com o mundo letrado. Minha intenção, ao trazer estes estudantes para o espaço, foi procurar atender, da melhor maneira possível, os alunos menores em termos de quantidade e qualidade de atenção.

Em 2012 e 2013 aprimorei essa participação, desenvolvendo um projeto de formação de mediadores de leitura ${ }^{8}$. Tal formação, realizada no contraturno escolar, me fez perceber o quanto a possibilidade de socializar e protagonizar atividades dentro da escola (re)aproximou os adolescentes da leitura. Pude constatar os resultados por meio de uma pesquisa realizada informalmente com estes educandos em 2013, na qual todos relataram um incremento do hábito e do prazer com a leitura, e de dados coletados junto ao sistema de empréstimo de livros. Desde então, mesmo tendo deixado a função de POSL, não deixei de refletir sobre as relações dos adolescentes e jovens com as práticas de leitura.

Tais reflexões originaram minha dissertação, ainda em andamento ${ }^{9}$. Além de abordagem teórica sobre o tema, realizei trabalho de campo junto a uma turma de $9^{\circ}$ ano e Professora

conceituais e metodológicas, sendo atualmente considerado um programa da Secretaria Municipal de Educação. O livro "45 anos: Sala e Espaço de Leitura" traz a trajetória do programa na rede municipal paulistana ao longo de sua existência. Disponível em: http://portal.sme.prefeitura.sp.gov.br/Portals/1/Files/45575.pdf. Acesso em: 30/08/2019. ${ }^{7}$ Os jovens e a leitura: uma nova perspectiva. São Paulo: Ed. 34, 2008; A arte de ler ou como resistir à adversidade. São Paulo: Ed. 34, 2009.

${ }^{8} \mathrm{Na}$ comunicação A quem cabe mediar leitura?, Sueli Bortolin informa que o termo mediador deriva do latim mediatore, e significa aquele que medeia ou intervém. Em se tratando de leitura, ela considera que o mediador do ato de ler é o indivíduo que aproxima o leitor do texto e que facilita esta relação. Neste sentido, podem ser considerados mediadores de leitura familiares, professores, bibliotecários, editores, críticos literários, redatores, livreiros e até amigos que nos emprestam um livro (BORTOLIN, 2001, p. 1).

${ }^{9}$ Vinculada à Linha de Pesquisa Linguagem e Arte em Educação do Programa de Pós-Graduação em Educação da Universidade Estadual de Campinas e ao Grupo de Pesquisa Alfabetização, Leitura e Escrita/Trabalho Docente na Formação Inicial (ALLE/AULA) sob a orientação do Prof. Dr. Ezequiel Theodoro da Silva. 
Orientadora de Sala de Leitura (POSL) do Fundamental 2 da EMEF Professor Antônio Duarte de Almeida ${ }^{10}$, localizada na zona leste da cidade de São Paulo.

Privilegiei o acompanhamento de uma turma de $9^{\circ}$ ano por ser frequentado por estudantes cuja faixa etária as edições de Retratos da Leitura no Brasil ${ }^{11}$, idealizadas pelo Instituto PróLivro, apontaram queda no gosto pela leitura. Como aponta João Luís Ceccantini, pesquisas recentes indicam que há um abandono paulatino das práticas de leitura à medida que os leitores recém-cultivados no Ensino Fundamental 1 vão deixando a infância e alcançando a juventude, em um processo gradativo que se intensifica ao longo da vida (2009, p. 210). Com o objetivo de investigar este possível distanciamento/abandono, busquei compreender se um projeto político pedagógico que incentive a participação dos estudantes e a escuta de suas reivindicações - a qual nomeio de "protagonismo juvenil" - facilita a (re)aproximação da leitura. Escolhi como lugar para esta investigação a Sala de Leitura da referida escola por ser a leitura a principal atividade desenvolvida no espaço. Fosse a observação realizada em aulas de Língua Portuguesa, a leitura seria uma entre outras atividades.

\section{Os adolescentes e a leitura}

Por ter grande interesse na literatura, o filósofo, pedagogo e psicólogo alemão Eduard Spranger (1882-1963) analisou a atração de certas formas de literatura ensinadas nas escolas secundárias alemãs. Ele afirmava que as leituras literárias do período clássico mais frequentemente incluídos no currículo tinham pouca atração, enquanto a literatura romântica alemã era a que mais se aproxima da estrutura psicológica do adolescente ${ }^{12}$. Da mesma forma, no campo musical, havia um maior interesse por Beethoven do que pelas obras de Mozart (MUUSS, 1974, p. 64).

A partir desta constatação de Spranger, me lembrei de uma experiência com um poema do Romantismo Brasileiro com educandos que à época estavam no $8^{\circ}$ ano. Fiz a leitura do poema e em seguida comecei a explicar algumas características do movimento, me detendo um pouco mais na segunda geração, aquela conhecida como ultrarromântica ${ }^{13}$. Achei que não haveria interesse da parte deles, mas fui surpreendida. Fizeram muitas perguntas sobre o amor e as formas de se relacionar, compreendendo que elas mudaram ao longo do tempo. Obviamente, naquele momento, estava tratando de uma temática que lhes interessava muito. Não obtive o mesmo sucesso quando tratei dos textos de caráter social da terceira geração.

Para elaborar a Matriz de Saberes do Currículo da Cidade de São Paulo, considerou-se a opinião de 43.655 estudantes do Ensino Fundamental da Rede Municipal de Ensino, que participaram, em 2017, de uma pesquisa sobre o que gostariam de vivenciar no currículo escolar. Aproximadamente 50\% apontaram gostar de participar de projetos culturais, práticas esportivas, informática e robótica. Neste quesito, "Eu acho legal participar de projetos", 29,3\% responderam que apreciam participar de projetos de leitura. Dos 10 itens mais votados, a leitura

\footnotetext{
${ }^{10} \mathrm{O}$ projeto de pesquisa passou por apreciação do Comitê de Ética em Pesquisa (CEP) da UNICAMP e foi aprovado sob o registro CAAE: 97483918.5.0000.8142.

11 A primeira edição desta pesquisa foi realizada em 2000 e divulgada em 2001, encomendada pela Câmara Brasileira do Livro, Snel e Abrelivros. Depois de 2007 ainda foram realizadas mais duas edições: 2011 e 2015.

${ }^{12}$ Lembro que esta questão foi abordada no primeiro ponto deste capítulo (p. 24), quando mencionei os trabalhos de Stanley Hall que, inspirado no romantismo alemão de Goethe e Schiller, descreveu a adolescência como sendo um período de Sturm und Drang: "tempestade e tensão" - ou "tempestades e tormentas", como aponta César.

${ }^{13}$ Entre seus representantes estão os poetas Álvares de Azevedo, Fagundes Varela, Casimiro de Abreu e Junqueira Freire, todos falecidos muito jovens. Algumas das características da segunda geração romântica são: forte egocentrismo, melancolia, pessimismo e negativismo; a presença constante e até exagerada do sentimentalismo; sentimentos ligados à exaltação da morte e idealização da infância.
} 
aparece em nono lugar, ficando à frente somente de projetos de Reforço Escolar. Esta pesquisa mostra o desprestígio que a leitura enfrenta entre os educandos da rede municipal.

A figura abaixo traz um quadro presente no dossiê escrito por Mansutti et al. para edição da revista Cenpec (2007, n. 4, p. 23) sobre quais tipos de atividades de lazer e culturais estavam entre as preferências dos estudantes, por faixa etária. Na observação, a informação de que apenas 1 aluna mencionou espontaneamente a leitura.

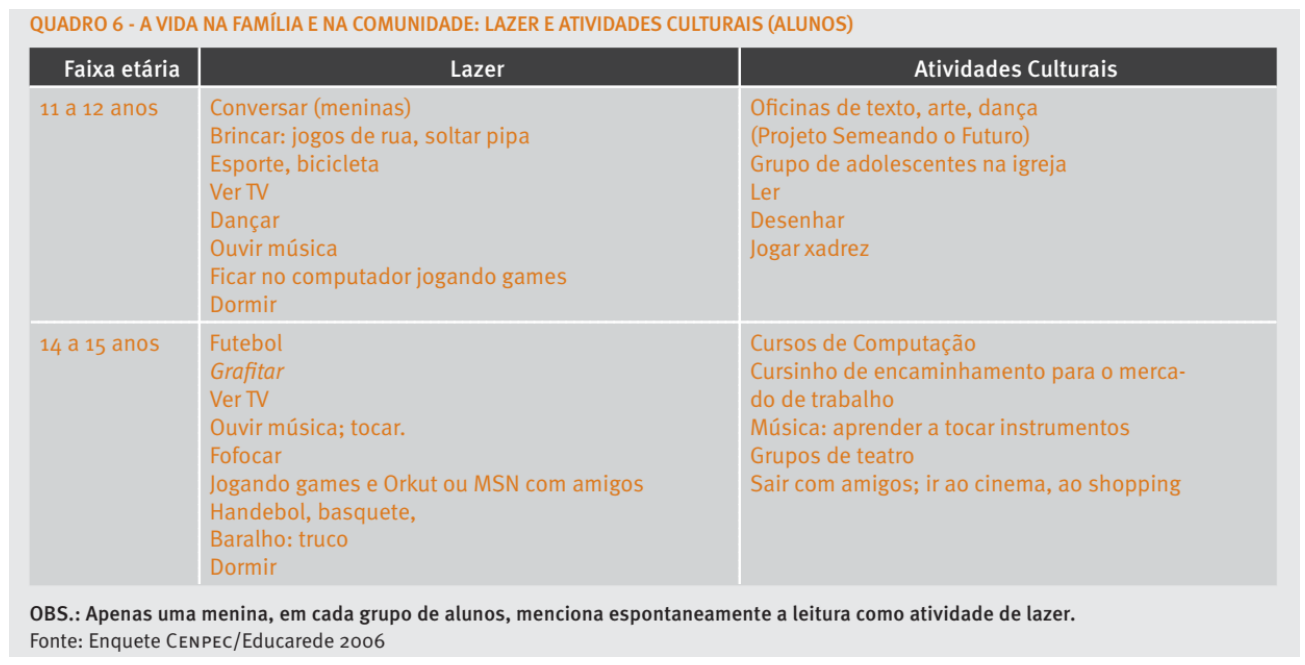

Figura 1 - Preferência de lazer e atividades culturais (alunos) - Fonte: Enquete CENPEC/Educarede 2006

$\mathrm{Na}$ faixa etária que interessa a este artigo (14 a 15 anos), observo uma grande preferência por atividades nas quais a socialização e estar em grupo sejam possíveis, como a prática de esportes coletivos, jogos de baralho, ouvir música e sair com amigos. Os grupos de amigos são espaços importantíssimos na busca de respostas para as questões que envolvem a adolescência (2007, n. 4, p. 10-11). Além disso, noto a preocupação com o futuro profissional, evidente por meio de escolhas como "curso de computação" e "cursinho de encaminhamento para o mercado de trabalho".

Mansutti et al. ainda mostram que poucos estudantes tinham material de leitura em casa e havia os que declararam ler apenas o livro didático, mesmo em casa, pois gostam de ler, mas não tinham acesso a outros materiais. Alguns mencionavam livros ou revistas retirados da biblioteca da escola e livros didáticos e paradidáticos emprestados pelos professores.

Para confirmar esta informação podemos usar os dados da pesquisa Retratos da Leitura no Brasil. Em 2001, ano de divulgação da primeira edição, o número de livros lidos entre os brasileiros havia sido 1,8 por ano. Em 2007, esse número chegou a 4,7 livros por habitante/ano, incluindo a média de 3,4 livros lidos por habitante/ano indicados pela escola. Uma das principais justificativas dessa elevação era a eficácia das políticas públicas de distribuição de $\operatorname{livros}^{14}$, que solucionou em grande parte a questão do acesso limitado e desigual aos materiais

\footnotetext{
${ }^{14}$ Em agosto de 2006, o Plano Nacional do Livro e Leitura, foi instituído pela portaria Interministerial N 1442. O PNLL é um conjunto de projetos, programas, atividades e eventos na área do livro, leitura, literatura e bibliotecas em desenvolvimento no país, empreendidos pelo Estado (em âmbito federal, estadual e municipal) e pela sociedade. É o maior programa de governo de distribuição de livros da América Latina e sua inovação está na iniciativa de juntar os esforços dos Ministérios da Educação e da Cultura, restituindo à leitura sua dimensão educacional e cultural. Sua prioridade é transformar a qualidade da capacidade leitora do Brasil e trazer a leitura para o dia-a-dia do brasileiro. Em $1^{\circ}$ de setembro de 2015, a então presidenta Dilma Rousseff assinou o Decreto $\mathrm{n}^{\mathrm{o}}$ 7.559, dispondo sobre o Plano Nacional do Livro e Leitura, dando-lhe assim uma maior dimensão que à

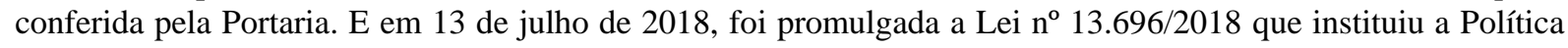
Nacional de Leitura e Escrita, tornando responsabilidade do Estado a construção e revisão permanentes de Planos voltados para o setor do livro, da leitura e das bibliotecas.
} 
de leitura. Em 2011, ano da terceira edição, a média caiu para 4,0 livros lidos por habitante/ano. Já em 2015, o número voltou a subir, chegando à média de 4,96. Tais oscilações apontam para a possibilidade de que as políticas públicas de distribuição de livros tenham garantido o acesso, mas não necessariamente a formação de leitores.

Desde sua primeira edição, Retratos se preocupa em entender a relação dos jovens com a leitura. Na análise que faz da edição de 2007 com dados relacionados aos jovens, a socióloga Zoara Failla foca a importância do impacto da participação das crianças e jovens na faixa de 5 a 17 anos, que representavam 49,6 milhões e correspondiam a quase $30 \%$ da amostra da pesquisa. Desse montante, $87 \%$ estavam na escola (43,2 milhões) sendo 84\% estudantes em escolas públicas (2008, p. 96-97). No entanto, $45 \%$ desses jovens informaram ler por obrigação, enquanto somente $26 \%$ o faziam por prazer. Failla constatou que não existia diferença significativa se se comparava a natureza da escola - pública ou privada - ou a classe social, mostrando que o problema de formar bons leitores não está apenas na esfera pública nem na diferença socioeconômica, como muitos apontam $^{15}$. Nesta mesma edição, Maria Antonieta da Cunha apontou a necessidade de a escola assumir verdadeiramente seu papel de formadora de leitores, intensificando sua ação em todas as direções que se relacionam com o gosto pela leitura (2008, p. 14).

Em sua terceira edição (2011), Retratos mostrou que os jovens que estudam leram uma média de 3,41 livros nos três meses anteriores à realização da pesquisa, enquanto os que não estavam estudando leram 1,13. Para Isis Valeria Gomes, editora, escritora e especialista em Literatura Infantil e Juvenil, tal resultado deixou em evidência que o "hábito" acaba após a saída da escola, pois o jovem perde a ambiência leitora, o grupo de amigos e a convivência com os livros (2012, p. 129). A pesquisa de 2015 confirmou esta percepção, mostrando um aumento significativo nos índices de leitura entre 5 e 17 anos.

Gomes ainda chama atenção para um equilíbrio entre o gostar e o não gostar de ler. Na faixa dos 11 a 13 anos estão aqueles que mais apreciam: 28\% gostam muito de ler, $52 \%$ gostam um pouco e $21 \%$ não gostam. Entre os 14 e 17 anos, os que não gostam são maioria: $31 \%$ contra $23 \%$ que apreciam muito ler, enquanto $46 \%$ gostam pouco. Tal redução nos índices a levou a colocar a seguinte questão: o que explica a redução do gosto após os 14 anos de idade?

Michèle Petit fornece algumas possibilidades de resposta ao apontar para a necessidade de se rever os discursos convencionais de elogio à leitura. Por serem oriundos e disseminados pelos poderes públicos, professores, pais ou editores, "podem ser percebidos como outras tantas ordens, como testemunhos de impaciência, de uma vontade de controle, de domínio", deixando pouco espaço para o desejo (2013, p. 21-22). Outra pista deste afastamento é dada quando comenta que a leitura pressupõe isolamento, uma ausência do grupo. Ora, estamos falando de um momento na vida, a adolescência, em que a vivência em grupo, a socialização, é considerada muito importante pelo jovem, conforme o quadro de resultados das preferências de lazer presente neste artigo.

Já Max Butlen, professor e pesquisador francês, em entrevista concedida às professoras Belmira Bueno e Neide Rezende, observa um divórcio entre a formação dos professores - no caso, ele fala do ensino médio - e a realidade das práticas culturais e vivências dos alunos, e entende que tais experiências referentes à leitura não são levadas em conta de modo muito forte e evidente (2015, p. 559).

O artigo de João Luís Ceccantini para o livro Mediação de Leitura soma à observação de Butlen ao colocar que o projeto que identificar a formação de leitores ao modelo tradicional do "ensino de literatura", fundado em conjunto de obras fechado e generalizado para qualquer contexto, estará fadado ao fracasso. Para ensinar a gostar de literatura será necessário lançar mão de uma postura não instrumental e de um conjunto bastante aberto de obras, contemplando

\footnotetext{
${ }^{15}$ Liam mais por exigência da escola - 46\% na escola pública e 44\% na particular; liam mais por obrigação - $63 \%$ nas famílias com renda acima de dez salários mínimos e $43 \%$ nas famílias com renda de um a dois salários.
} 
não só aquelas inseridas no cânone, mas também aqueles textos capazes de "estabelecer um diálogo vibrante com referências que sejam significativas para o grupo de crianças ou jovens com os quais o mediador quiser interagir" (2009, p. 229-230).

Ceccantini também propõe como caminho uma animação de leitura adaptada para jovens com ênfase na questão da socialização, conciliando a dimensão essencialmente solitária da leitura e a forte tendência juvenil para a convivência em grupo que ajuda o jovem na construção de sua identidade individual. Dá como exemplo de práticas mais ligadas à sociabilidade os fanfictions, as séries, os blogs, que têm na Internet seu suporte básico ${ }^{16}$, e aponta o quanto a sociedade e a escola estão longe de lhes oferecer este tipo de experiência.

No que diz respeito à animação de leitura, a questão do protagonismo juvenil, que faz com que os jovens se vejam como sujeitos capazes de agir no seu contexto social, estaria mais afinada com a sociabilidade almejada pela juventude, tanto porque

se fundamenta na ação direta, propícia ao trabalho cooperativo, quanto porque se dirige para a comunidade, envolvendo potencialmente o jovem numa vasta teia de relações. Uma animação de leitura que, além do protagonismo, também se propuser incorporar a ideia do 'trabalho voluntário' certamente constituirá uma alternativa a mais nesse esforço de levar o jovem a viver experiências intensas com a leitura, particularmente com a leitura literária $\left(2009\right.$, p. 226) ${ }^{17}$.

\section{O protagonismo juvenil}

Como relatado neste artigo, a motivação para a pesquisa de mestrado que desenvolvo nasceu da minha prática enquanto POSL e da necessidade de dar conta de demandas das turmas de Fundamental 1 ( $1^{\circ}$ a $5^{\circ}$ anos). Seguindo práticas que já eram desenvolvidas por outros colegas da Diretoria Regional na qual estava lotada, convidei alguns estudantes dos anos finais do Fundamental 2 para serem monitores e me auxiliarem com os estudantes menores.

Tal atividade levou esses estudantes-monitores a um maior engajamento com a leitura, pois encontraram a possibilidade de ficar em grupo e experienciar a autonomia, tão cara aos adolescentes. Com o tempo, passaram a sugerir algumas ações que gostariam de desenvolver na Sala de Leitura. Percebi, então, que escutar e acolher estas ideias e colocá-las em prática era algo importante, já que revelavam o desejo de participar das escolhas que estavam sendo feitas para eles na escola. Na sala de aula o corpo docente se mostrava surdo às demandas e necessidades dos estudantes. No que dizia respeito à gestão, o mesmo acontecia. Mesmo com a representação discente no Conselho de Escola suas demandas não eram ouvidas e atendidas, posto que esta instância decisória é dominada pelas vozes adultas, mais preocupadas em manter a ordem, a hierarquia e a disciplina.

Logo, com o projeto, os poucos adolescentes que participavam - era um grupo de 5 ou 6 estudantes - podiam atender a algumas necessidades: serem ouvidos e acolhidos em suas propostas, experimentar a autonomia e estar em grupo. Chamei então a atuação dos estudantes de "protagonismo", em consonância com a forma como essa participação vem sendo nomeada por documentos oficiais de órgãos governamentais - como a Base Nacional Comum Curricular e o Estatuto da Juventude, por exemplo - e organismos internacionais como a Unesco, por exemplo. Com esta definição fujo, portanto, da armadilha semântica (Ferreti et al., 2004, p.

\footnotetext{
16 “São demonstrações concretas dessa necessidade que os jovens têm hoje de explorar até mesmo o universo da literatura de uma forma que implique interação permanente entre pares" (CECCANTINI, 2009, p. 224).

${ }^{17}$ A questão do trabalho voluntário aparece porque na pesquisa Diálogos com o mundo juvenil (2005) ele é visto como elemento aglutinador dos jovens em torno de causas as mais variadas. Ver Ceccantini, 2009, p. 225-226.
} 
422) na qual o conceito de protagonismo juvenil caiu, ressignificando-o de modo a me afastar do endosso à ordem neoliberal e à responsabilização do indivíduo pela sua manutenção, e tornando-o uma proposta de ação e participação real dos estudantes.

\section{5. "Da monitoria da sala de leitura [eu participo] porque eu gosto. Me atrai."}

Dadas as características do objeto de estudo proposto - compreender as relações dos adolescentes dos anos finais do Ensino Fundamental 2 com a prática de leitura e verificar se ações pautadas no protagonismo juvenil facilitam esse relacionamento -, a abordagem qualitativa é a mais apropriada. Segundo Godoy, a pesquisa qualitativa ocupa "um reconhecido lugar entre as várias possibilidades de se estudar os fenômenos que envolvem os seres humanos e suas intrincadas relações sociais, estabelecidas em diversos ambientes" (1995, p. 21). Dentre os diferentes caminhos possíveis, escolheu-se o estudo de caso, caracterizado "como um tipo de pesquisa cujo objeto é uma unidade que se analisa profundamente” (idem, p. 25).

Fontes variadas de informação foram utilizadas para a realização do trabalho de campo, sendo a primeira o acompanhamento de aulas de uma turma de $9^{\circ}$ ano em Sala de Leitura. Nestas aulas pude centrar a atenção nos participantes e nas práticas de leitura ali realizadas. Aproveitei a ocasião para estreitar a relação com alguns adolescentes, principalmente aqueles que participavam das aulas e emprestavam livros, perguntando o que estavam levando e o que lhes motivou a escolhê-lo.

A segunda fonte de dados foi uma produção textual na qual os adolescentes escreveram sobre sua experiência com a leitura e a leitura na escola. Entendo que há uma distância entre a experiência pessoal destes adolescentes com a leitura e a experiência vivida com a leitura na escola. Dezenove educandos fizeram a produção e deste conjunto, pude aproveitar 16 textos ${ }^{18}$.

A terceira fonte são as entrevistas com 8 adolescentes e a POSL, as quais servem ao propósito de aprofundar a compreensão de sua relação com a leitura e sua prática na escola, a percepção de protagonismo que possuem e se há influência na (re)aproximação da prática leitora. As entrevistas, individuais, foram realizadas a partir de roteiros semiestruturados, tendo como base o roteiro elaborado por Pasquali (2014) em sua dissertação.

A escolha dos adolescentes a serem entrevistados ocorreu a partir da produção textual, considerando os seguintes critérios:

1. Impacto que a leitura da produção provocou na pesquisadora;

2. A menção ao gosto pela leitura;

3. Escolha de um escritor ou uma escritora de quem gostassem;

4. O fato de assumir uma posição argumentativa, justificando e sustentando sua opinião.

Considerei o Projeto Político Pedagógico da escola uma quarta fonte por trazer especificidades que fogem às práticas realizadas nas escolas da rede municipal paulistana, a saber: a reorganização dos tempos e espaços destinados à aprendizagem dos educandos, e a crítica ao modelo tradicional de ensino à medida que o coletivo da escola foi instituindo os projetos interdisciplinares. A prática que vem sendo construída desde 2016 comunga, segundo o PPP, com uma escola aberta, democrática, participativa, autônoma, investigativa e autoral,

\footnotetext{
${ }^{18}$ Dezesseis adolescentes e seus responsáveis assinaram os termos de autorização propostos pelo Comitê de Ética e Pesquisa. Um adolescente não quis dar continuidade à sua participação, a responsável por uma adolescente não quis que a filha participasse da pesquisa, e outro adolescente não frequenta a escola assiduamente, tornando impossível a coleta dos termos.
} 
"em que alunas e alunos constituem-se como sujeitos históricos em cada momento de sua vida, e que professoras e professores sejam sujeitos do processo educativo escolar" (2009, p. 81-82).

Para este artigo analiso as informações referentes ao único garoto que compõe a seleção e que a princípio não se enquadrava nos critérios acima elencados. No entanto, em setembro de 2019, houve na escola uma competição Interescolar de Slam ${ }^{19}$, na qual foi premiado em segundo lugar. Este resultado, segundo ele, mudou sua relação com a leitura.

Sobre o que mais gosta de fazer na escola, o adolescente diz:

E: Aqui, no horário de aula, eu gosto bastante de ficar os meus tempos livres, conversando mesmo com os meus amigos, que a maioria é de outra sala, e no horário fora de aula eu gosto de ficar muito aqui, na monitoria da Sala de Leitura. P: Então você é monitor na Sala de Leitura?

E: Sim.

Logo neste trecho, merece destaque a participação do adolescente no projeto de monitoria de Sala de Leitura desenvolvido no contraturno escolar pela POSL responsável pelas turmas de Fundamental 1. Deste projeto, que conta com a participação de outros estudantes além dele, ele diz participar por "gosto" e por se "sentir atraído". Tal afirmação corrobora a citação feita a Ceccantini no encerramento do terceiro tópico deste artigo sobre o trabalho cooperativo ser atraente para o adolescente.

Quando pergunto sobre as atividades desenvolvidas na monitoria, conta que

E: A gente auxilia a professora em tudo, tudo. A gente auxilia ela, por exemplo, a arrumar a Sala de Leitura, pegar alguém se precisar dar aula mesmo, a gente vai e auxilia ela na aula. Por exemplo no... Agosto Indígena. Nós monitores demos uma mão mesmo. Por exemplo, eu fazia o papel de professor, mais ou menos, ela só auxiliava a gente. Mas como era dentro do planejamento, tava certo.

Mesmo ignorando o conceito de protagonismo juvenil - apesar de ser mencionado no Projeto Político Pedagógico da escola e considerado um dos pilares de sua prática, no sentido de tornar as relações escolares mais democráticas e os estudantes mais autônomos e participativos -, entendo que para "exercer" o papel que lhe foi dado o adolescente dele se apropria, uma vez que participa na proposição e execução das propostas. Nesta participação, além da satisfação em realizar algo, ele também encontra satisfação na socialização em grupo:

E: Saber que eu estou aqui num grupo de pessoas, que me ajudam, que deixam eu ajudar, que me aceitam do jeito que eu sou, e não criticam pelo que eu fiz alguns tempos atrás, pelo jeito que eu era. Só me ensinaram a ser uma pessoa melhor.

A leitura o encanta, sendo inclusive uma resposta aos momentos de tristeza:

\footnotetext{
${ }^{19}$ Os slams são campeonatos de poesia nos quais os participantes têm até três minutos para apresentarem sua performance - uma poesia de autoria própria sem formato definido, sem adereços ou acompanhamento musical. O texto pode ser escrito previamente, mas também pode haver improvisação. O júri é escolhido na hora e dá notas de 0 a 10 , que podem ser fracionadas. Entre todos os competidores, a maior nota vence. O slam foi criado nos anos 1980 em Chicago, nos Estados Unidos, ao mesmo tempo em que a cultura hip hop tomava forma, mas só chegou ao Brasil mais tarde, nos anos 2000. (LIMA, Juliana Domingos de. "O que são slams e como eles estão popularizando a poesia". Disponível em: https://www.nexojornal.com.br/expresso/2016/12/20/O-que-s\%C3\%A3o-slams-e-como-eles-est\%C3\%A3opopularizando-a-poesia. Acesso em: 11/11/2019.)
} 
E: Porque, por exemplo, como eu disse mesmo na minha redação, gosto muito de ler livros de filmes. Só que assim, lendo livros de filmes, como eu mesmo disse ali, dá pra mim (sic) perceber todos os detalhes. Muitos detalhes que eu não tinha percebido em séries ou filmes, independente. E isso me encanta demais porque tem uma coisa ou outra que faz diferença na história, querendo ou não.

$[\ldots]$

$P:$ E você acha que a leitura poderia ser uma resposta a esta chateação?

E: Com certeza! Porque tem muita coisa em livros, independente do livro, que ajudam bastante. Bastante não, ajudam... tipo, é a peça que faltava pra eu ficar bem.

O adolescente conta que os livros lidos em 2019 ou foram emprestados da Sala de Leitura, ou ganhou através de um programa de distribuição de livros reabilitado no final de 2018 pela Secretaria Municipal de Educação chamado "Minha Biblioteca", cujo objetivo é incentivar o gosto pela leitura por meio da formação de pequenas bibliotecas nas casas dos estudantes, aumentando a presença destes materiais no espaço doméstico. Seja como for a forma de contato com a leitura, é importante frisar que o adolescente tem acesso através da escola e da política pública de aquisição e distribuição de livros.

A família não o incentiva à leitura, mas a escola, na figura da Professora Orientadora de Sala de Leitura, cumpre perfeitamente esta função, uma vez que seu papel é:

E: Incentivar. Incentivar porque a leitura está se perdendo cada vez mais. Isso não tem nem o que dizer. Tudo, a cultura brasileira, tudo está se perdendo, e os livros estão ficando aí parados.

A forma que ela encontra para cumprir com sua função, segundo o adolescente é

E: Falando sobre os Slams e da poesia, incentivando a gente a escrever e a ler também. Por exemplo, no dia do Slam eu ganhei um livro da Tauane Teodoro. E isso também me incentivou a querer mais pegar livro de poesia, porque antes eu não curtia tanto, só ouvia música. E ela incentivou assim. Em mim tocou desse jeito. Em outras pessoas, não sei... Por exemplo, uma colega da minha sala, ela, as amigas dela, são incentivadas de outro jeito, porque a professora empresta até livros dela mesma para as meninas da minha sala. E incentivou deste jeito.

A professora é um "gênio", pois parece adivinhar o que ele quer:

E: (...) Porque tudo que eu quero da Sala de Leitura, ela consegue propor. Por exemplo, da poesia, nossa, foi... sei lá... uma coisa que me puxou e ajudou demais, porque, por exemplo, por causa da professora eu entrei no Slam. Eu não era pra entrar no Slam, eu nem tinha ideia, tinha vergonha, timidez. E por causa dela que eu consegui entrar no Slam. Foi uma coisa que eu gostei demais. Ela deu aquilo que eu queria, que era da poesia.

Interpreto esta fala como mais uma pista de que o incentivo ao protagonismo pode aproximar e favorecer a relação do adolescente com a leitura. Ao se preparar para os Slams, o adolescente mobiliza as leituras e pesquisas que faz. Esta ação e curiosidade são instigadas, a meu ver, não só pela predisposição do estudante e sua boa relação com a leitura, mas também pela prática pedagógica desenvolvida na escola através do trabalho da POSL. 
O fato de a professora incentivar e acolher as sugestões dos adolescentes também é levada em consideração pelo estudante:

E: Ela faz o máximo possível. O máximo não, o máximo impossível pra fazer de tudo pela gente. A sala pode não retribuir, mas ela faz de tudo.

P: Você a considera disponível para ouvir os adolescentes?

E: Sempre.

P: E ela costuma atender as sugestões que vocês dão?

E: Sim.

Por fim, pergunto se o estudante vê alguma relação entre o fato dele gostar de ler e a escola oferecer espaços de escuta e participação para os adolescentes:

E: Sim. O meu gosto por leitura aumentou demais, demais mesmo, com a influência da escola por causa da monitoria da Sala de Leitura. Como eu fico das 13 h30 até às $18 h 20$ aqui, eu não ia ficar também sem fazer nada, então me despertou mais esse desejo de ler. Eu rodeado de livro, muita coisa chama atenção, capa, título, tudo chama atenção, aí me desperta a vontade de ler.

Esta fala me remete à minha experiência profissional, também narrada neste artigo, e que motivou a pesquisa que ora desenvolvo. Oferecer espaços de escuta e participação aos adolescentes, aliados a uma prática pedagógica diversificada e que leve em consideração seus interesses, pode sim ser uma possibilidade de reaproximar os jovens da leitura.

\section{Referências}

BECKER, Daniel. O que é adolescência? São Paulo: Brasiliense, 2003 ( $5^{\mathrm{a}}$ reimp. da $13^{\mathrm{a}}$ ed. de 1994).

BUENO, Belmira Oliveira; REZENDE, Neide Luzia de. Formador de leitores, formador de professores: a trajetória de Max Butlen. Educ. Pesqui., São Paulo, v. 41, n. 2, p. 543-564, junho de 2015. Disponível em: http://www.scielo.br/scielo.php?script=sci_arttext\&pid=S151797022015000200543\&lng=en\&nrm=iso. Acesso em: 05/04/2017.

CALligARIS, Contardo. A adolescência. São Paulo: Publifolha, 2013. (Folha Explica).

CECCANTINI, João Luís. Leitores iniciantes e comportamento perene de leitura. In: SANTOS, Fabiano dos; MARQUES NETO, José Castilho; RÖSING, Tânia M. K. Mediação de Leitura: discussões e alternativas para a formação de leitores. São Paulo, Global, 2011.

CUNHA, Maria Antonieta. Acesso à leitura no Brasil. In: AMORIM, Galeno (Org.). Retratos da leitura no Brasil. São Paulo: Imprensa Oficial: Instituto Pró-livro, 2008. Disponível em http://prolivro.org.br/home/images/antigo/1815.pdf. Acesso em: 16/08/2017.

EMEF PROFESSOR ANTÔNIO DUARTE DE AMEIDA. Projeto Político Pedagógico. 2019.

FAILLA, Zoara. Os jovens, leitura e inclusão. In: AMORIM, Galeno (Org.). Retratos da leitura no Brasil. São Paulo: Imprensa Oficial: Instituto Pró-livro, 2008. Disponível em: http://prolivro.org.br/home/images/antigo/1815.pdf. Acesso em: 16/08/2017. 
GOMES, Isis Valeria. Retrospectiva - O acesso ao livro e à leitura pelos jovens no Brasil. In: FAILLA, Zoara (Org.). Retratos da Leitura no Brasil 3. São Paulo: Imprensa Oficial do Estado de São Paulo: Instituto Pró-Livro, 2012.

FERRETTI, Celso J.; ZIBAS, Dagmar M. L.; TARTUCE, Gisela Lobo B. P. "Protagonismo Juvenil na literatura especializada e na reforma do Ensino Médio". Cadernos de Pesquisa, v. 34, n. 122, p. 411-423, maio/ago. 2004.

GODOY, Arilda Schmidt. Pesquisa qualitativa: tipos fundamentais. Rev. adm. empres., São Paulo, v. 35, n. 3, p. 20-29, Junho 1995. Disponível em: http://www.scielo.br/scielo.php?script=sci_arttext\&pid=S0034-

75901995000300004\&lng=en\&nrm=iso. Acesso em: 03/11/2019.

MANSUTTI, Maria Amabile; ZELMANOVITS, Maria Cristina; CARVALHO, Maria do Carmo Brant de; GURIDI, Verônica. Educação na segunda etapa do Fundamental. Cadernos Cenpec, São Paulo, n. 4, jul./dez. 2007, p. 7-45.

MUSS, Rolf E. Teorias da Adolescência. Interlivros: Belo Horizonte, 1974.

PASQUALI, Matheus Boucault de. Juventude e participação: os sentidos da experiência juvenil em duas escolas municipais de Campinas - SP. 2014. 161f. Dissertação (Mestrado). Programa de Pós-Graduação em Educação, Universidade Federal de São Carlos, Campus Sorocaba, Sorocaba, SP.

PETIT, Michèle. Leituras: do espaço íntimo ao espaço público. São Paulo: Ed. 34, 2013.

SECRETARIA MUNICIPAL DE EDUCAÇÃO. Coordenadoria Pedagógica. Currículo da Cidade: Ensino Fundamental: componente curricular: Língua Portuguesa. 2. ed. São Paulo: SME/COPED, 2019.

\section{Sobre a autora}

Thais Batista Siqueira é professora de Fundamental 2 na rede municipal de ensino de São Paulo e mestranda no programa de Pós-Graduação da Faculdade de Educação da Unicamp, dedicando-se ao estudo da relação entre adolescência e leitura.

E-mail: thasiqueira@yahoo.com.br. 